\title{
Hot Deformation Behaviour and Processing Maps of an As-Cast Mg-6.8Y-2.5Zn-0.4Zr Alloy
}

\author{
Madlen Ullmann ${ }^{1, a^{*}}$, Matthias Schmidtchen ${ }^{1}$, Kristina Kittner ${ }^{1}$, \\ Thorsten Henseler ${ }^{1}$, Rudolf Kawalla ${ }^{1}$ and Ulrich Prahl ${ }^{1}$ \\ ${ }^{1}$ Institute of Metal Forming, Technische Universität Bergakademie Freiberg, Freiberg, Germany \\ aMadlen.Ullmann@imf.tu-freiberg.de, \\ ${ }^{*}$ corresponding author
}

Keywords: Flow curve, dynamic recrystallization, processing map, LPSO phase.

\begin{abstract}
Deformation behaviour of an as-cast Mg-6.8Y-2.5Zn-0.4Zr alloy during plane strain compression was characterized in this work by high-temperature testing. Based on the experimental data, the values of strain rate sensitivity, efficiency of power dissipation and the instability parameter under the condition of various hot working parameters were investigated. Processing maps were established by superimposing the instability map over the power dissipation map, this being connected with microstructural evolution analysis in the hot deformation processes.

Accompanied microstructure characterization of the binary $\alpha-\mathrm{Mg} /$ Long Period Stacking Ordered (LPSO) microstructure reveals that the flow behaviour is related to the deformation mechanisms. At lower temperatures $\left(350-400{ }^{\circ} \mathrm{C}\right)$ formation of kink bands is observed, which normally occur when deformation twinning is inhibited and other slip systems are strongly hindered by the complex LPSO structures. Dynamic recrystallization (DRX) was initiated at higher temperatures above $400{ }^{\circ} \mathrm{C}$, influencing the softening behaviour of the material significantly. DRX was the main softening mechanism when deformation takes place at $500{ }^{\circ} \mathrm{C}$ and the kink band deformation decreased.
\end{abstract}

\section{Introduction}

Many researchers have studied Mg alloys containing rare earth elements such as $\mathrm{Y} / 1 /$ or Gd /2/ because of their high strength and creep resistance and weak texture $/ 3,4 /$. But only a limited number of studies have been conducted on the hot compressive properties and processing maps of LPSOcontaining Mg-Y-Zn-Zr alloy. Li et al. /5/ investigated the hot deformation behaviour and processing maps of as-cast $\mathrm{Mg}-10 \mathrm{Gd}-4.8 \mathrm{Y}-2 \mathrm{Zn}-0.6 \mathrm{Zr}$ alloy. The optimum parameters for the hot working of the alloy were the deformation temperature of $500{ }^{\circ} \mathrm{C}$ and strain rate of $0.01 \mathrm{~s}^{-1}$. However, microstructure analysis reveals only a simple description of recrystallization rather than a systematic study on the important second-phase LPSO in this alloy during hot deformation. $N$. Tahreen et al. $/ 6 /$ studied the hot working behaviour of as-extruded ZM31+6Y alloy, with particular emphasis on the mechanisms of LPSO phase. Kink bands, which are involved in an essential deformation mechanism, have been observed by the motion of dislocation pairs. Generally, it is reported, that kink band deformation is an essential deformation mechanism of the LPSO phase due to homogenous strains generated in the crystals during plastic deformation and therefore contributing to increased strength and ductility /10/.

J. Wang et al. /7/ calculated processing maps of the homogenized Mg-Gd-Y-Zn-Mn alloy that was deformed at strain values of 0.6 and 1.2. According to the maps, the optimal processing conditions are in the temperature range of 460 to $500{ }^{\circ} \mathrm{C}$ and in the strain rate range of 0.001 to $1 \mathrm{~s}^{-1}$ or in the temperature range of 350 to $500{ }^{\circ} \mathrm{C}$ and strain rate range of 0.001 to $0.005 \mathrm{~s}^{-1}$. The LPSO phase of the homogenized Mg-Gd-Y-Zn-Mn alloy has high ductility after being compressed to a large strain. The kink band is observed in the LPSO phase due to the movement of the dislocation. In addition, the lamellar phases become stream-shaped phases after hot deformation.

However, to the authors' knowledge, materials behaviour during forging or rolling of cast $\mathrm{Mg}$ $6.8 \mathrm{Y}-2.5 \mathrm{Zn}-0.4 \mathrm{Zr}$ alloy is not well known. Thus, in the present study, the hot deformation behaviour of as-cast Mg-6.8Y-2.5Zn- $0.4 \mathrm{Zr}$ alloy based on simulation tests was investigated, and processing maps were drawn. The goal was to understand the dynamic recrystallization (DRX) under different 
processing conditions for a cast state and to optimize the hot working parameters of this alloy during hot processing, such as rolling.

Theory of processing maps. Processing maps based on the dynamic material model (DMM) is a very useful tool for optimizing hot processing parameters. They are often used to understand the hot workability of many materials, especially those that are difficult to deform. Processing maps are described as a function of temperature and strain rate using the dynamic material model (DMM) based on the variations of stability parameters. DMM was proposed by Prasad et al. to analyze hot forming with the following objectives: (a) to determine the microstructural response of the sample in the axes of the machining parameters, (b) to study the behaviour of materials within a continuum approach, which simulates the forming of metals. This model considers the mechanical processing as a kind of system and the hot deformed sample as a complete dissipator of the total input power $(P)$. The total input power is divided into two parts, i.e. the sum of two integrals as defined by Eq. (1), the sensitivity of the strain rate $(m)$ being given by Eq. (2).

$$
\begin{gathered}
P=G+J=\int_{0}^{\dot{\varepsilon}} \sigma \mathrm{d} \dot{\varepsilon}+\int_{0}^{\sigma} \dot{\varepsilon} \mathrm{d} \sigma=\sigma \dot{\varepsilon} \\
\left(\frac{\partial J}{\partial G}\right)_{T, \varphi}=\frac{\sigma \mathrm{d} \dot{\varepsilon}}{\dot{\varepsilon} \mathrm{d} \sigma}=\left[\frac{\partial \ln \sigma}{\partial \ln \dot{\varepsilon}}\right]_{T, \varphi}=m
\end{gathered}
$$

Most of the energy was dissipated by the temperature rise given by the first integral ( $G$ content) and the rest is determined by the use of microstructural changes such as recovery and dynamic recrystallization (stability domains) and material damage (instability domains), as indicated by the second integral ( $J$ co-content). A polynomial equation is used to fit the experimental data for $\ln \sigma$ and can be expressed as:

$$
\ln \sigma=a+b \ln \dot{\varepsilon}+c(\ln \dot{\varepsilon})^{2}+d(\ln \dot{\varepsilon})^{3} .
$$

By polynomial regression, the constants $(a, b, c$, and $d$ ) can be obtained at different forming temperatures. The strain rate sensitivity $m$ can be calculated by the following equation:

$$
m=b+2 c \ln \dot{\varepsilon}+3 \mathrm{~d}(\ln \dot{\varepsilon})^{2} .
$$

Overprinting two cards, the power dissipation efficiency map $(\eta)$ and the instability map $(\xi(\dot{\varepsilon}))$, at constant logarithmic strain will yield to a processing card. The power dissipation efficiency $(\eta)$ and the instability parameter $(\xi(\dot{\varepsilon}))$ given first by Prasad et al. are given by the Eq. (5) and (6).

$$
\begin{aligned}
& \eta=\frac{2 m}{m+1} \\
& \xi(\dot{\varepsilon})=\frac{\partial \ln \left(\frac{m}{m+1}\right)}{\partial \ln \dot{\varepsilon}}+m \leq 0
\end{aligned}
$$

The negative values of $\xi(\dot{\varepsilon})$ indicates that the rate of entropy production caused by microstructural change is lower than the rate of entropy externally applied via thermomechanical processes. The processing maps combine information on the efficiency of dissipation $(\boldsymbol{\eta})$ with the position of the regions of instability $(\xi(\dot{\boldsymbol{\varepsilon}})<0)$ in the temperature - strain rate - region in a two-dimensional graph. 


\section{Material and Experimental Procedures}

Material: The chemical composition of the Mg-6.8Y-2.5Zn- $0.4 \mathrm{Zr}$ alloy in weight percent utilized in this work is presented in Table 1. The raw material was produced via conventional casting methods.

Table 1: Chemical composition of the Mg-6.8Y-2.5Zn-0.4Zr alloy (wt-\%) via optical emission spectrometry (OES)

\begin{tabular}{lllllllll}
\hline $\mathrm{Zn}$ & $\mathrm{Zr}$ & $\mathrm{Y}$ & $\mathrm{Si}$ & $\mathrm{Fe}$ & $\mathrm{Ni}$ & $\mathrm{Cu}$ & Others & $\mathrm{Mg}$ \\
\hline 2.5 & 0.4 & 6.8 & 0.01 & 0.005 & 0.001 & 0.001 & 0.01 & Bal. \\
\hline
\end{tabular}

Compression tests: In a servo-hydraulic hot forming simulator, plane strain tests were performed under process-oriented conditions. A graphite/oil mixture was used as a lubricant to reduce friction on the contact surfaces between the sample and the tool. The isothermal flow curves were obtained from the recorded force-displacement data, taking into account the correction of the measured values for dissipation energy and friction, applying the correction function by Siebel /18/, coefficient of friction $\mu=0.12$. Softening effects due to an increase in temperature from dissipated forming energy were eliminated numerically by use of the thermodynamic temperature factor $K_{\vartheta}=\exp \left(-m_{1} * \vartheta\right)$ with $m_{1}=-0.00427{ }^{\circ} \mathrm{C}^{-1}$. The deformation temperature $\left(325-525^{\circ} \mathrm{C}\right)$ was adjusted with an air circulation furnace and kept at this temperature for 15 minutes to homogenize the temperature in the cross section. This was followed by continuous compression tests with strain rates of $0.01-10 \mathrm{~s}^{-1}$. Graphite was used as lubricant. Subsequently, the samples were deformed to an equivalent logarithmic strain of $\varphi_{v}=1.2$. At least three tests were performed for each forming condition to ensure a sufficient level of statistical safety.

Microstructure investigation. The microstructural changes in the material during and after the compression tests were analyzed in quenched specimens. The microscopic images of the compressed deformation specimens were recorded at the respective locations, with the local logarithmic strain within the sample corresponding to the total logarithmic strain. For the optical analysis, the samples were separated, cold embedded, ground and polished with an OP-suspension. Etching was performed with a picric acid solution consisting of $70 \mathrm{ml}$ ethanol, $10 \mathrm{ml}$ distilled water, $10 \mathrm{ml}$ glacial acetic acid and $4.2 \mathrm{~g}$ picric acid. In addition, investigations were carried out with the scanning electron microscope (SEM) of the Stahlzentrum Freiberg e. V.

\section{Results and Discussion}

Microstructure of as-cast alloy. Fig. 1 (a) and (b) show the microstructure of the Mg-6.8Y-2.5Zn$0.4 \mathrm{Zr}$ alloy in the as-cast state, which is composed of two phases: the $\alpha$ magnesium matrix, which is made up of globulites with an average size of approximately $76 \mu \mathrm{m}$, measured by the linear intercept method and the LPSO phase, which precipitates network-like along the grain boundaries and as fine lamellae within the Mg matrix. According to EDX analysis and previous investigations /8/, the network-like structures are the $\mathrm{Mg}_{12} \mathrm{YZn}$ phase, already known as the LPSO phase /9/. Transmission electron microscope (TEM) analysis has revealed that the fine lamellae are enriched with the alloying elements $\mathrm{Y}$ and $\mathrm{Zn}$.
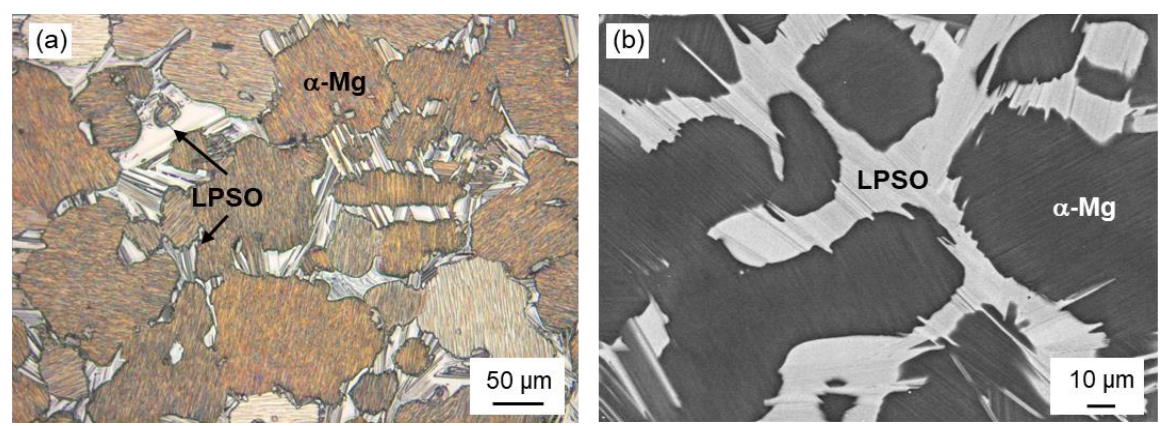

Fig. 1: Typical microstructures of the as-cast Mg-6.8Y-2.5Zn-0.4Zr alloy: (a) light microscopic and (b) scanning electron microscopic image as well as 
Flow curve. Fig. 2 shows as an example the flow curves of the cast alloy $\mathrm{Mg}-6.8 \mathrm{Y}-2.5 \mathrm{Zn}-0.4 \mathrm{Zr}$, which was compressed at temperatures of 325 to $525^{\circ} \mathrm{C}$, as well as the strain rates of 0.1 to $5 \mathrm{~s}^{-1}$. The flow curves at 0.01 and $10 \mathrm{~s}^{-1}$ were also determined, but are not shown here. It can be seen that the hardening and softening behaviour of the specimens is sensitive to both temperature and strain rate. In particular, the yield stress increases as the temperature decreases and as the strain rate increases. This phenomenon is parallel to the fact that the rate of dislocation multiplication increases with the increase in the strain rate and then impedes the movement of the dislocation, leading to an increase in yield stress. In addition, the accumulated critical shear stress for the non-basal sliding process of the $\mathrm{Mg}$ matrix decreases significantly with the increase in forming temperature and at higher forming temperatures dynamic recovery occurs $\left(\right.$ at $400{ }^{\circ} \mathrm{C}$ ) or a dynamic recrystallization $\left(\right.$ at $475^{\circ} \mathrm{C}$ ) so that the yield stress decreases rapidly.

If the samples were deformed at $325-375^{\circ} \mathrm{C}$, softening during compression could not be obtained. Due to flow instability, the samples crack early, implying that stress hardening dominated plastic deformation.


Fig. 2: Exemplary flow curves of as-cast $\mathrm{Mg}-6.8 \mathrm{Y}-2.5 \mathrm{Zn}-0.4 \mathrm{Zr}$ alloy during plane strain compression at temperatures of $325-525^{\circ} \mathrm{C}$ as well as strain rates of $0.1-5 \mathrm{~s}^{-1}$

Processing map. The flow curves were energetically analyzed via DMM to generate a twodimensional representation, derived from the superposition of two-dimensional graphs in terms of isolines called processing map. With this representation general information on dynamic recrystallization (DRX), recovery, superplasticity, failure (cracking) plus possibly formation of hard particles and of deformation bands can be generated.

A typical processing map for as-cast Mg-6.8Y-2.5Zn-0.4Zr at a logarithmic strain of 0.4 (typical logarithmic strain in a rolling pass) is shown in Fig. 3. The contour numbers represent percent power dissipation efficiency and the shaded domains indicate the regions of flow instability. The processing map exhibit two domains with flow instability. The instability domain \#1 occurs at strain rates below $1 \mathrm{~s}^{-1}$ while domain \#2 occurs at higher strain rates $\left(\approx 1-10 \mathrm{~s}^{-1}\right)$.

In this study, deformation kink bands occurred within the LPSO phase as well as within the $\mathrm{Mg}$ matrix (Fig. 4 (a,b)) with kinking angles ranging from 30 to $60^{\circ}$. Liu et al. $/ 11 /$ have attributed the formation of kink boundaries to the arrangements of basal dislocations, which align perpendicular to the slip plane. Yu et al. /2/ described, that the LPSO phase inhibits basal dislocation movement, which causes dislocation accumulation at the boundaries between the LPSO phase and the Mg matrix. Consequently, the LPSO phase bends to different degrees, resulting in strong stress fields along the $\mathrm{LPSO} / \alpha-\mathrm{Mg}$ interface and kink deformation occurs. In domain \#1 this phase creates the unstable flow at low temperatures probably by causing strain localization concentrated around the LPSO phase. In some areas even cracks could be found in the interface between the matrix and LPSO phase (see Fig. 4 (b)). As mentioned above, the microstructure is in the instability domain, so cracks easily occur. In 
addition, the stress concentration induced at the interface can act as a cause for dislocation nucleation and, especially at higher temperatures, for the formation of new grain boundaries. The occurrence of dynamically recrystallized grains (Fig. 5 (c)) in the $\alpha$-Mg matrix is mainly derived from the interface between the Mg matrix and LPSO structures. Within the LPSO phase no DRX could be observed. At higher temperatures the kink band deformation decreased, and as it was already shown in the flow curves the volume fraction of dynamically recrystallized grains increased (Fig. 5 (a) and (b)). This is due to the facilitation of dislocation gliding and climbing at elevated temperatures. The kink deformation is reduced due to the occurrence of basal slip, non-basal slip, sliding and climbing of dislocations at elevated temperatures $/ 2 /$.

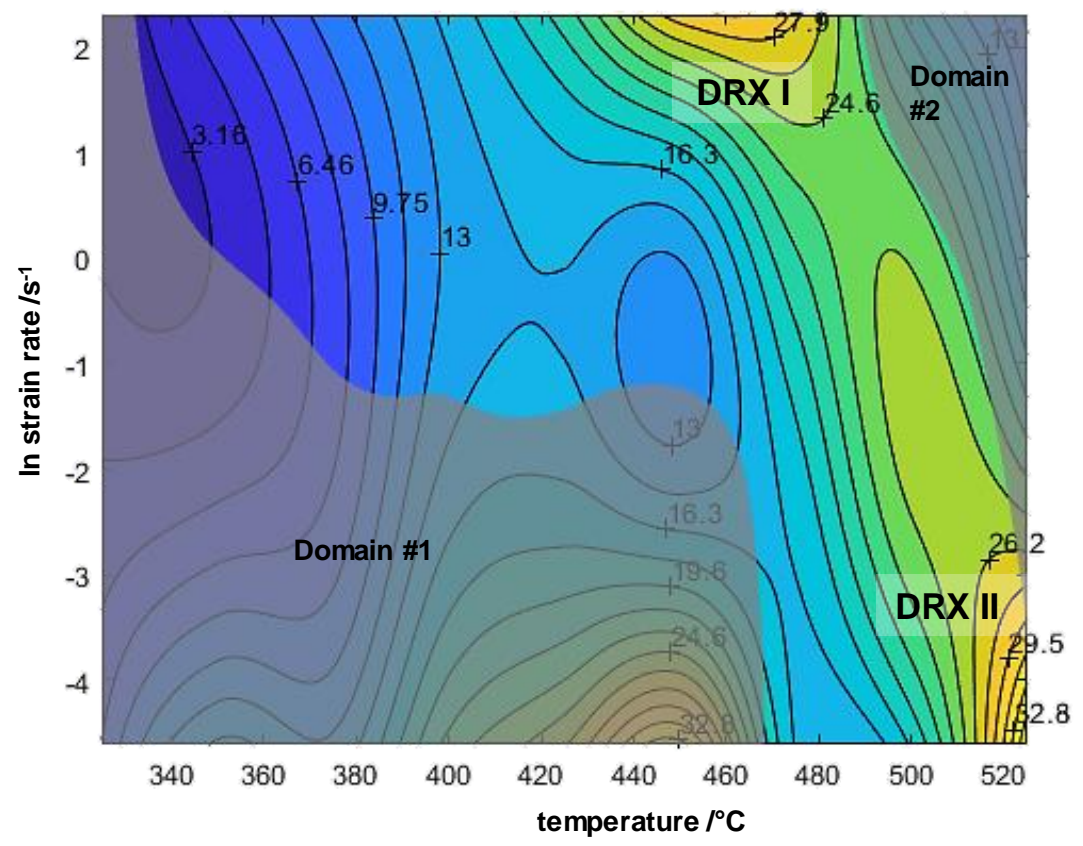

\begin{tabular}{|l|l|l|}
\hline $\begin{array}{l}\text { Domain } \\
\text { \#1 }\end{array}$ & $\begin{array}{l}325- \\
475^{\circ} \mathrm{C}\end{array}$ & $\begin{array}{l}0.01- \\
1 \mathrm{~s}^{-1}\end{array}$ \\
\hline $\begin{array}{l}\text { Domain } \\
\text { \#2 }\end{array}$ & $\begin{array}{l}500- \\
525^{\circ} \mathrm{C}\end{array}$ & $\begin{array}{l}1- \\
10 \mathrm{~s}^{-1}\end{array}$ \\
\hline
\end{tabular}

Fig. 3: Processing map for as-cast $\mathrm{Mg}-6.8 \mathrm{Y}-2.5 \mathrm{Zn}-0.4 \mathrm{Zr}$ at an equivalent logarithmic strain of 0.4

Generally, instability associated with high strain rate is due to localized shear /12/. The deformed microstructure in these instability regions (domain \#2) are shown in Fig. 4 (c) corresponding to the forming conditions $525^{\circ} \mathrm{C} / 1 \mathrm{~s}^{-1}$, respectively. Fig. 4 (c) does not exhibit any apparent banding instead it shows a coarse recrystallized grain structure. The absence of shear banding in the microstructure may be due to covering of the as-deformed microstructural features by recrystallized grains with grain growth taking place after deformation. In addition, the LPSO phases act as strong barriers against grain boundaries migration at high strain rates and high temperatures.

Domains \#1 and \#2 (instability regions) are undesirable for processing and hence should be avoided. Although the resulting microstructures in the DRX domains have different grain sizes, they have corrugated grain boundaries with some fine grains nucleating at the boundaries. These regions are suitable for hot rolling, extrusion and forging.
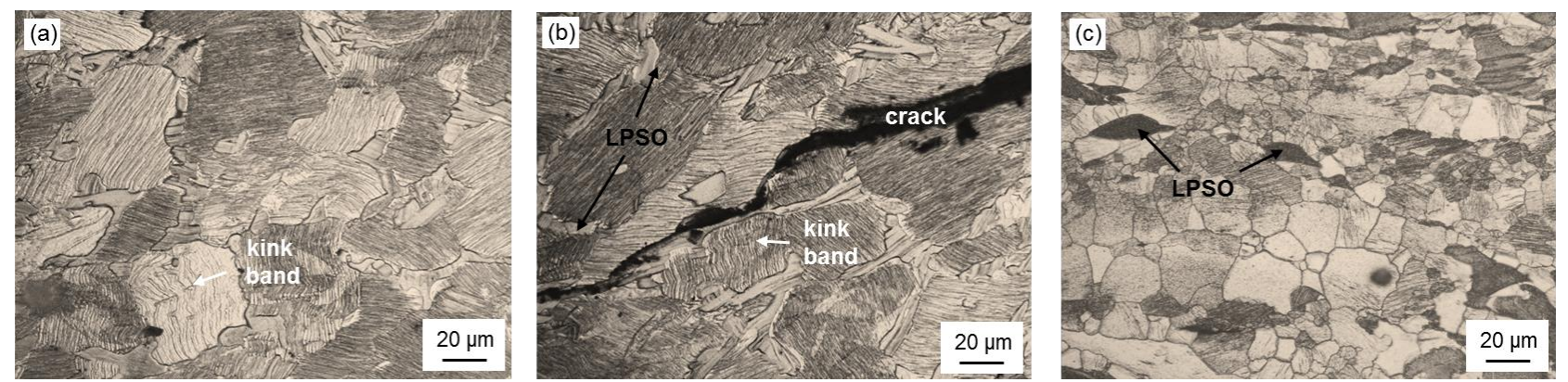

Fig. 4: Microstructures in the instability domains corresponding to the forming condition (a, b) $350{ }^{\circ} \mathrm{C} / 0.1 \mathrm{~s}^{-1}$ and (c) $525^{\circ} \mathrm{C} / 1 \mathrm{~s}^{-1}$ 

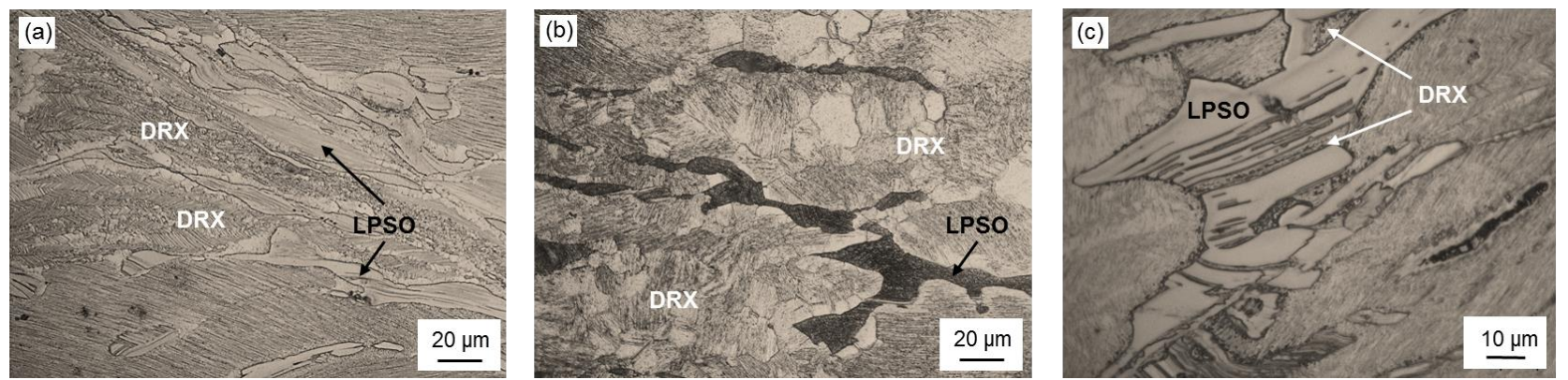

Fig. 5: Microstructures in regions where dynamic recrystallization (DRX) takes place corresponding to the forming condition (a) $450{ }^{\circ} \mathrm{C} / 10 \mathrm{~s}^{-1}$ and (b) $525{ }^{\circ} \mathrm{C} / 0.1 \mathrm{~s}^{-1}$, (c) DRX occurring along the LPSO/ $\alpha-\mathrm{Mg}$ interface

Analysis of hot compressive deformation behaviour. The study of plastic flow characteristics is needed as it explains why the values of the power dissipation efficiency $(\eta)$ and the instability parameter $(\xi(\dot{\varphi}))$ differ according to temperatures, logarithmic strains and strain rates in the processing map. The power law relationship of Sellars and Tegart's /13, 14/ was used to explain the deformation mechanism during hot deformation over wide ranges of temperature and strain rate. The parameters of this equation were obtained from the mean values of the slopes of graphs relating flow stress to strain rate and temperature in linear dependence (well adjusted), see Figs. $7-9$ and are represented in the following:

$$
\dot{\varepsilon}=4.23 \cdot 10^{19} \cdot[\sinh (0.01068 \cdot \sigma)]^{5.76} \cdot \exp \left(-\frac{279.8}{8.314 \cdot T}\right)
$$

The model coefficients determined are valid in the temperature range from 325 to $525{ }^{\circ} \mathrm{C}$ as well as for equivalent strain rates of 0.01 to $10 \mathrm{~s}^{-1}$. As written in the relation above, the average activation energy for plastic flow $Q$ of the as-cast Mg-6.8Y-2.5Zn- $0.4 \mathrm{Zr}$ alloy is calculated as $279.8 \mathrm{~kJ} / \mathrm{mol}$. The activation energy $Q$ is a significant parameter that indicates deformation difficulty degree during hot deformation and is influenced by concurrent dynamic precipitation, dislocation pinning effect and the second phase. The activation energy of as-homogenized Mg-Gd-Y-Zn-Mn alloy containing LPSO phase was determined to be $260.94 \mathrm{~kJ} / \mathrm{mol}$ by Wang et al. $/ 7 /$. Chen et al. /15/ obtained a $Q$ of 209 $\mathrm{kJ} / \mathrm{mol}$ for as-cast $\mathrm{Mg}-\mathrm{Zn}-\mathrm{Y}-\mathrm{Zr}$ alloy containing $\mathrm{W}$-phase. These values are higher than that in pure magnesium, which is $135 \mathrm{~kJ} / \mathrm{mol}$. Obviously, the activation energy of the here presented alloy (279.8 $\mathrm{kJ} / \mathrm{mol}$ ) increases strongly because of the presence of the thermally stable LPSO phase, which could be huge barrier to the motion of dislocation. Because of the high $Q$ value, a difficult hot deformation of this alloy is likely.
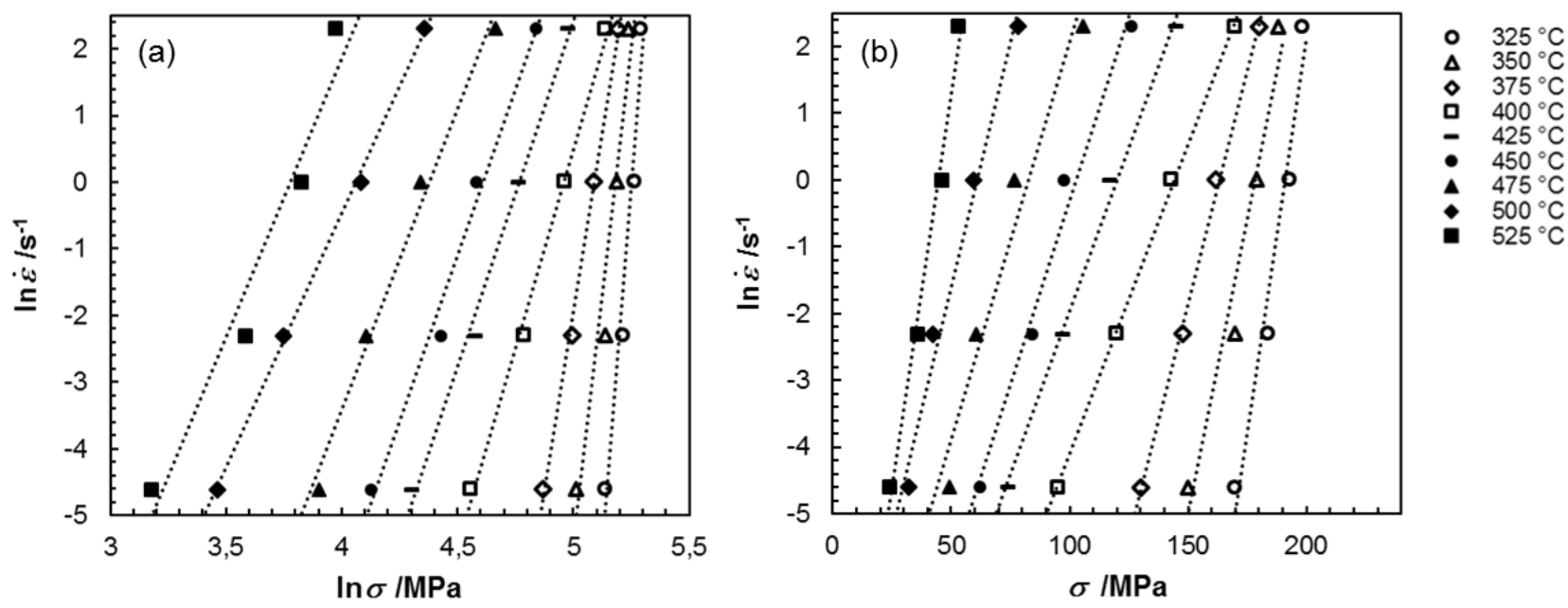

Fig. 6: Relationship between $\ln \dot{\varepsilon}$ and (a) $\ln \sigma$ (b) $\sigma$ 

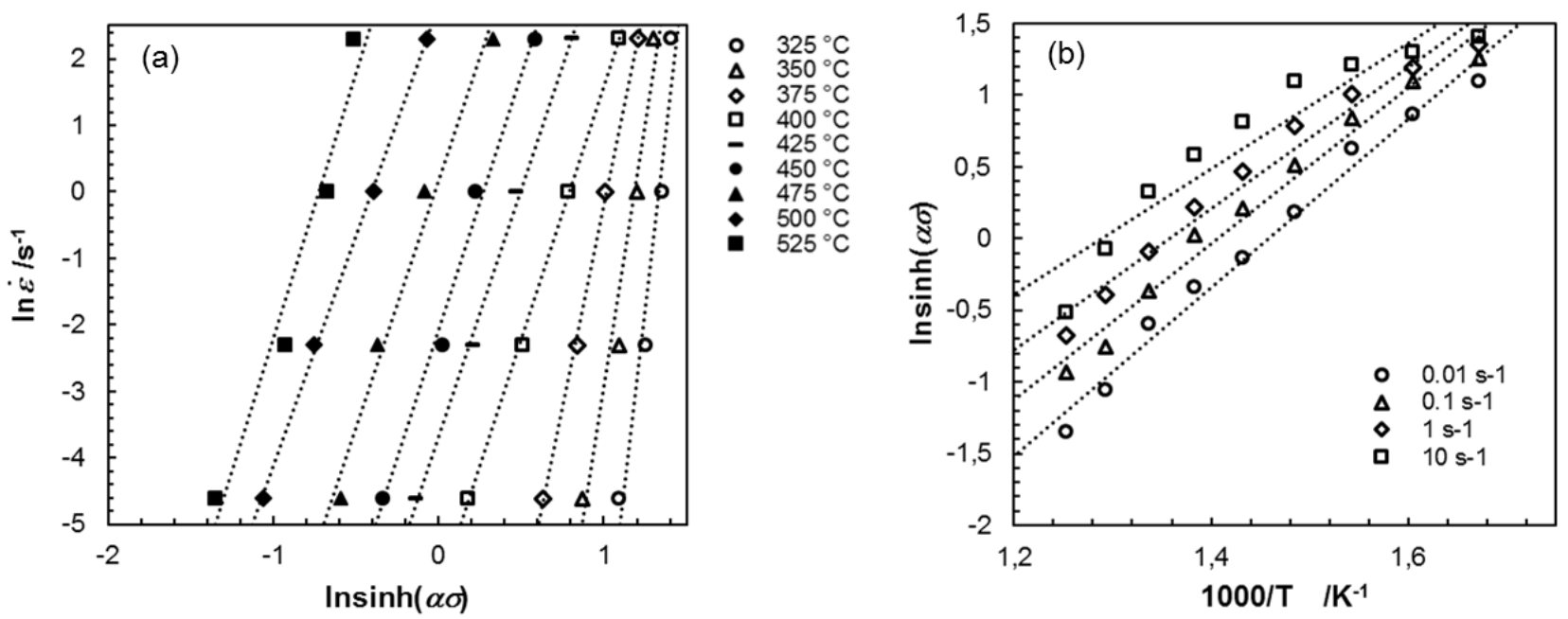

Fig. 7: Relationship between of (a) $\ln \dot{\varepsilon}-\ln [\sinh (\alpha \cdot \sigma)]$ and (b) $\ln [\sinh (\alpha \cdot \sigma)]-1 / T$ at different strain rates

Fig. 8 shows the dependence of $\ln Z$ to $\ln [\sinh (\alpha \cdot \sigma)]$, where $Z$ is the Zener-Hollomon parameter $(Z=\dot{\varepsilon} \exp (Q /(R T)))$. The fitting of this relationship is necessary for the interpretation of power law relationship. In this research a good fit of the hyperbolic sine function with the correlation value for the linear regression $\left(R^{2}\right)$ of 0.9602 was found for low $Z$ values. Therefore, the following constitutive equation can be drawn by plot at the logarithmic strain of 0.4 :

$$
Z=4.23 \cdot 10^{19} \cdot \sinh ^{5.76}(0.01068 \cdot \sigma)
$$

The model coefficients determined allow the complete description of the Zener-Hollomon parameter in the temperature range from 325 to $525{ }^{\circ} \mathrm{C}$ as well as for equivalent strain rates of 0.01 to $10 \mathrm{~s}^{-1}$. The stress exponent $n$ at low $\mathrm{Z}$ values (low strain rates and high temperatures) is 5.76. It is considered to be that $n>5$ associated with dislocation climb creep ( $n=5$ means lattice-diffusion controlled dislocation climb creep and $n=8$ means pipe-diffusion controlled dislocation climb creep) and $n=3$ with solute drag creep /16/. So the $n$ value in this research is 5.76, suggesting that power-law creep (probably lattice-diffusion controlled dislocation climb creep) dominates the plastic flow.

When the $\ln Z$ value further increases, the data deviate from the linearity, because of power law breakdown (PLB) associated with $n>8$ occurs at high strain rates and low temperatures. It is admitted that shear banding occurs in the PLB regime. In the PLB regime, it has been proposed that dislocations have less time to rearrange and thus do not have the ability to sweep out excess vacancies that are created during plastic deformation at high strain rates $/ 17 /$. Fig. 8 (a) shows the plot of $\ln Z$ $\ln [\sinh (\alpha \cdot \sigma)]$, constructed with an activation energy $Q=279.8 \mathrm{~kJ} / \mathrm{mol}$ and the fitting parameter $\alpha=0.01068 \mathrm{MPa}^{-1}$. Compared with the curves in Fig. 8 (b), the degree of linearity has been improved as anticipated from the characteristic hyperbolic sine function. However, the data at large $Z$ values are still quite non-linear. Most of the deviated data belong to the instability regime in the processing map (Fig. 3). This result indicates that the data in the instability regime are beyond the validity of PLB regime that can be described by Sellars and Tegart's sinh formula, e.g. (8). 

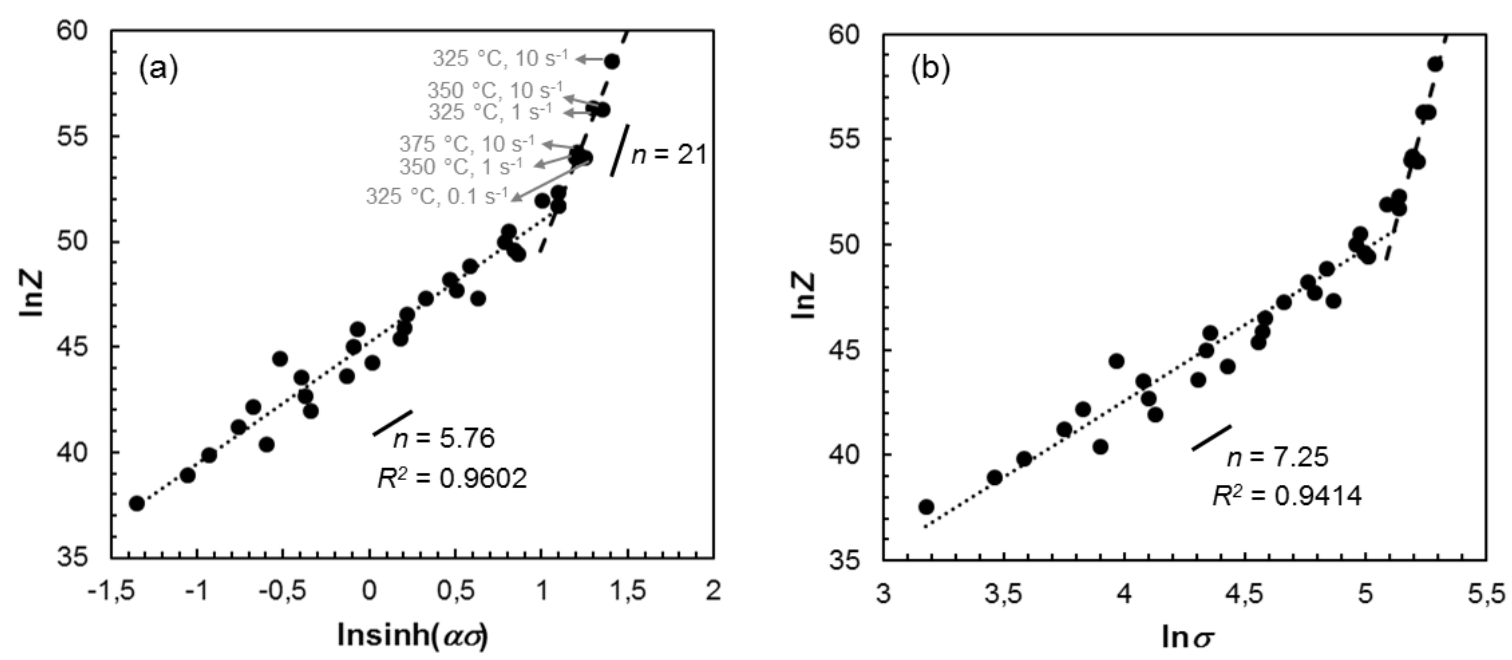

Fig. 8: Relationship between (a) $\ln Z-\ln [\sinh (\alpha \cdot \sigma)]$ and (b) $\ln Z-\ln \sigma$

\section{Conclusion}

1) Based on the DMM, the processing map of the as-cast $\mathrm{Mg}-6.8 \mathrm{Y}-2.5 \mathrm{Zn}-0.4 \mathrm{Zr}$ alloy that was deformed at logarithmic strain value of 0.4 was established. According to the map, the optimal processing conditions are in the temperature range of $475-525^{\circ} \mathrm{C}$ and strain rates below $1 \mathrm{~s}^{-1}$ or in the temperature range of $340-390{ }^{\circ} \mathrm{C}$ and strain rate range of $0.5-10 \mathrm{~s}^{-1}$.

2) The activation energy of the as-cast $\mathrm{Mg}-6.8 \mathrm{Y}-2.5 \mathrm{Zn}-0.4 \mathrm{Zr}$ alloy is obtained to be $279.8 \mathrm{~kJ} / \mathrm{mol}$. Compared with pure magnesium, the presence of LPSO phase results in higher activation energy. Based on the hyperbolic sine law, the constitutive equation is

$$
\dot{\varepsilon}=4.23 \cdot 10^{19} \cdot[\sinh (0.01068 \cdot \sigma)]^{5.76} \cdot \exp \left(-\frac{279.8}{8.314 \cdot T}\right) .
$$

\section{Acknowledgements.}

The Institute of Metal forming would like to express its sincere thanks to the Stahlinstitut Freiberg for their support in the acquisition of scanning electron microscope images of the initial state.

Funding. The research was carried out within the framework of the AMARETO project. The "Saxon Alliance for Material and Resource Efficient Technologies" (AMARETO) is funded by the European Union (European Regional Development Fund) and the Free State of Saxony.
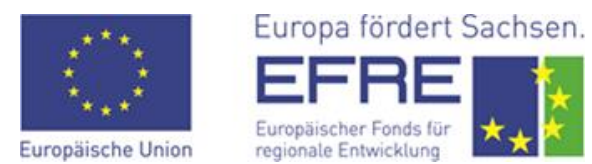

\section{References}

[1] J.-K. Kim, S. Standlöbes, D. Raabe, On the room temperature deformation mechanisms of a Mg-Y-Zn alloy with long-period-stacking-ordered structures, Acta Materialia 82, pp. 414-423, 2015

[2] J. Yu, Z. Zhang, Q. Wang, X. Yin, J. Cui, H. Qi, Dynamic recrystallization behaviour of magnesium alloys with LPSO during hot deformation, Journal of Alloys and Compounds 704, pp. 382-389, 2017

[3] D. Griffiths, Explaining texture weakening and improved formability in magnesium rare earth alloys, Materials Science and Technology 31 (1), pp. 10-24, 2015 
[4] A. Imandoust, C.D. Barret, T. Al-Samman, K.A. Inal, H. El Kadiri, A review on the effect of rare-earth elements on texture evolution during processing of magnesium alloys, Journal of Materials Science 52, pp. 1-29, 2017

[5] H.Z. Li, H.J. Wang, Z. Li, C.M. Liu, and H.T. Liu, Flow Behaviour and Processing Map of AsCast Mg-10Gd-4.8Y-2Zn-0.6Zr Alloy, Mater.Sci. Eng. A, 528, pp. 154-160, 2010

[6] N. Tahreen, D.F. Zhang, F.S. Pan et al., Characterization of hot deformation behaviour of an extruded $\mathrm{Mg}-\mathrm{Zn}-\mathrm{Mn}-\mathrm{Y}$ alloy containing LPSO phase, Journal of Alloys and Compounds, 644, pp. 814 ff., 2015

[7] J. Wang, F. Xie, S. Liu, S. Huang, F. Pan: Hot Deformation Behaviour and Processing Maps of As-Homogenized Mg-Gd-Y-Zn-Mn Alloy, Rare Metal Materials and Engineering, 47(6), pp. 1700-1707, 2018

[8] K. Neh, M. Ullmann, et al.: Mechanical properties and microstructure of the magnesium alloy Mg-6.8Y-2.5Zn-0.5Al produced by casting and hot rolling, Materials Science Forum 918, pp. $3-12,2018$

[9] J. Geng, X. Teng, et al.: Microstructure transformations in the heat-treated Mg-Zn-Y alloy. In: Journal of Alloys and Compounds 577, pp. 498-506, 2013

[10] H. Gao, K. Ikeda, T. Morikawa, K. Higashida, H. Nakashima, Analysis of kink boundaries in deformed synchronized long-period stacking ordered magnesium alloys, Materials Letters 146, pp. 30-33, 2015

[11] H. Liu, J. Ju, X. Yang, J. Yan, D. Song, J. Jiang, A. Ma, A two-step dynamic recrystallization induced by LPSO phases and its impact on mechanical property of severe plastic deformation processed $\mathrm{Mg}_{97} \mathrm{Y}_{2} \mathrm{Zn}_{1}$ alloy, Journal of Alloys and Compounds 704, pp. 509-517, 2017

[12] Y.V.R.K. Prasad, S. Sasidhara, Hot Working guide: A compendium on Processing Maps, ASM International, Metals Park, OH, 1997.

[13] Garofalo, Fundamentals of Creep and Creep-Rupture in Metals, McMillan Series in Materials Science, McMillan, New York, 1965.

[14] J. Weertman, Dislocation climb theory of steady-state creep, ASM Trans. Quavt. Metal. Sci. J1, 61, pp. 681-694, 1968

[15] Q. Chen, X. Xia, B. Yuan, D. Shu, Z. Zhao, J. Han, Hot workability behaviour of as-cast MgZn-Y-Zr alloy /J/ Materials Science and Engineering A, 593, pp. 38-47, 2014

[16] O.D. Sherby, E.M. Taleff, Influence of grain size, solute atoms and second-phase particles on creep behaviour of polycrystalline solids Materials Science and Engineering A322, pp. 89-99, 2002

[17] D.R. Lesuer, C.K. Syn, O.D. Sherby, An evaluation of power law breakdown in metals, alloys, dispersion hardened materials, and compounds, in: E.M. Taleff, C.K. Syn, D.R. Lesuer (Eds.), Deformation, Processing and Properties of Structural Materials, pp. 81-194, 2000

[18] E. Siebel: Die Formgebung im bildsamen Zustande, theoretische Grundlagen der technischen Formgebungsverfahren, Stahleisen, Düsseldorf (1932) 